\title{
The Influence of Transformational Leadership on the Level of TQM Implementation in the Higher Education Sector
}

\author{
Hassan A. A. Argia ${ }^{1} \&$ Aziah Ismail ${ }^{1}$ \\ ${ }^{1}$ School of Educational Studies, Universiti Sains Malaysia, Penang, Malaysia \\ Correspondence: Hassan A. A. Argia, School of Educational Studies, Universiti Sains Malaysia, 11800 Penang, \\ Malaysia. Tel: 60-017-336-1260. E-mail: ha74aa@yahoo.com
}

Received: November 12, 2012

Accepted: December 7, 2012 Online Published: January 27, 2013

doi:10.5539/hes.v3n1p136

URL: http://dx.doi.org/10.5539/hes.v3n1p136

\begin{abstract}
This current research paper investigates the role of transformational leadership on impacting the level of TQM implementation in the higher education sector. In addition, TQM, as a management philosophy, can be implemented successfully only when incorporated into the prevailing learning organization and adequate understanding of transformational leadership. The understanding of the relationship between the two represents a useful starting point into gaining an insight of TQM implementation in the higher education institutes. In order to build a strong foundation for the current research pivotal relevant review of previous literatures was initiated. The review assisted the researcher in formulating the research objectives, questions, aims and framework. The quantitative and qualitative research methods were used to derive the relationship between the variables of the study. A total number of 500 lecturers were selected randomly in order to exemplify the questionnaire raised topics complex. The findings of the current research indicated that transformational leadership dimension have positive influences and significant towards the practices of TQM in the selected universities.
\end{abstract}

Keywords: transformational leadership, TQM, Libyan higher education

\section{Introduction}

The international business and global management impact on higher education have placed challenges for higher education institutions (HEIs) to be in line with the globalization needs. Many countries around the world are now moving towards 'mass' higher education (Moi, 2006) in order to meet such current challenges. In addition, Van Vught (1996) asserts that adequate quality management is needed in higher education which the procedure and method consider as a mean to help higher education institutions to achieve their quality management purposes. In Libya the rapid evolution in the number of institutions of higher education led to the low level of performance of many of these institutions.

The low level of performance is caused by several factors, including lack of faculty specialists, weak institutional infrastructure, lack of equipment necessary for educational activities, and absence of quality programs for such institutions. For example, there are a large number of students in departments and disciplines not required by the society and the labor market (Abu Jaafar, 2009), aside from the quantitative and qualitative evolution in the provision of services. The United Nations Educational, Scientific, and Cultural Organization estimates that the proportion of the quantitative increase in the number of students in higher education in Libya is the highest level among Arab states (Bashir, 2005).

Thus as many developed countries, Libya prioritized the quality of her higher education as this level of education produce human capital for nation development (Al-Mansouri, 2004; Ali, 2005). Furthermore, higher education is a fundamental part of the infrastructures of the overall national development and it is a key factor in building capabilities and skills, in accordance to this fact, the Libyan government enriched the higher education sector with experts from the public planning council, whom were asked to prepared a national strategy targeted to develop higher education in Libya (Theeb, 2009; Al-Mansouri, 2004). Moreover,

The national strategy for higher education in Libya has outlined plans which need to be followed by higher education management system which has to diagnose and identify problems, develops visions and goals, and identify the executive steps. The most important priorities proposed by this strategy are the reformation of the administrative and financial system to ensure the independence of universities as without this, no real change can 
be made or be effective (Theeb, 2009). However, AbdulKarim (2010) explained that, for the time being, these branches are still ineffective which is a big issue faced by the (HEIs) in Libya.

Theeb (2009) indicated that despite of the fact that most institutions of higher education in Libya have established centers for quality, there is diversity in the level of universities and colleges in terms of the implementation of activities and assessment tools for quality and institutional performance. His results showed that the organizational culture is still not encouraging for the implementation of evaluation activities and quality assurance. The most important needs at the individual level is to provide lectures to widen the awareness of the importance of quality and evaluation activities.

According to Koch (2003), there are many critical issues which hinder the implementation of TQM in higher education institutions such as leadership, customer identification, and organizational transformation. Unlike business organizations, chancellors and leaders of higher education institutions do not own ultimate authority and the necessary resources. Lack of necessary authority makes it difficult to arrange their values and goals through layers of higher education institutions.

While higher education institutions are places for learning and creating knowledge throughout their research, it is ironic that they have been lagging behind other organizations in implementing TQM. This failure is due to structural and traditional characteristics of higher education institutions (Tartouri and Jwayhan, 2006). Ali and Shastri (2010) noted that higher education institutions which have deep-rooted traditions dating back to numerous centuries are reluctant to change. Universities and colleges are organized based on departmental units. In adopting TQM, organizations culture move from product focus to market focus. The faculty's primary loyalty is directed towards the academic field. Market requirements for their students are of secondary importance, except for some professional schools such as business and engineering. In business organizations there is a cross linkage and sophisticated communication among various functional departments. In contrast, most of the individual departments of higher education institutions operate in vacuum. Leaders of higher education institutions who want to be competitive in today's fast paced, ever-changing world must be able to effectively and efficiently react to the change and also be able to implement change in response (Gulam, 2005).

AbdulKarim (2010) stressed that Libyan university leaders need to develop their managerial competence by providing them with knowledge and organizational skills that help them to implement various plans. Although some TQM practices have been unsuccessful, previous empirical research showed that TQM has a positive effect on organizational performance, including innovational performance.

Previous studies have indicated that higher education in Libya is going through critical stages and has arrived at low levels. Poor management in Libyan universities and colleges is another problem as they do not follow international standards (National Report on Human Development, 2002). Al-Manssouri (2004) confirmed that higher education institutions (HEIs) require actual reformation, starting with the philosophy, aims, policies, strategies, plans, structures, curricula, methods, and techniques. As a result, TQM was implemented in 2004 to address the issue of quality in HEIs in Libya.

While discussing Libyan higher education, El-Hawat (2006) noted that HEIs lack quality and sound policies which in turns led to a decline at all levels, especially in the last decades. The Center for Quality Assurance (2009) affirmed that there is a need to review regulations and procedures in HEIs and the university leaders need to adopt a culture of quality.

The traditional model of the leader as head is being increasingly recognized as no longer appropriate and applicable in higher education. Transformational leadership has increasingly become associated with individuals at different levels within an organization. Moreover, transformational leadership is strongly associated with the effectiveness of leadership throughout the organization (Inman, 2007; Antonaros, 2010).

\section{Research Objectives}

This study examines the part transformational leadership play in TQM implementation in Libyan public universities. It targets to highlight the role of effective transformational leadership in upgrading TQM performance.

In order to attain to the aim of the study the current research paper attempts to answer the following research question:

- Is there any influence of transformational leadership on the level of TQM implementation?

\section{Review of Literature}

In the current research relevant findings from previous studies were highlighted and critically discussed to create 
the basis for the possible outcomes of the current study. The focus of the reviewed literature was to identify the role of transformational leadership in TQM implementation in Libyan public universities.

\subsection{Quality Management}

One of the major obstacles in the empirical investigations of quality in organizations has been the difficulty in defining precisely what quality is.). According to Bergman and Klefsjö (2003), good quality is the means by which organizations increase their profits. Good quality increases the satisfaction and loyalty of the target customers and eventually causes cost decrease. Additional costs result from redoing given tasks. Furthermore, good quality work increases the productivity of the company. In the last few years, members of educational institutions worldwide have been giving due attention to the quality of education. Educators consider quality as an element in the educational priority. Moreover, the quality of education is reflected in the levels of the knowledge, abilities, and skills of students chosen for various jobs with different demands and personal qualifications. Researchers argue that quality learning is a pivotal aspect in forming the future of the individual. In addition, quality learning is important in the labor market policies and the globalized labor quality movement worldwide.

To compete with other leading organizations worldwide, a developed system of higher education places efficiency as the sole criterion in its development process. Effective higher education system is pivotal in creating strong human resources that advance the future of nations. This system should include quality management improvement as a first step in the creation of a strong organization that targets satisfying various stakeholders, such as students and parents, among others. A system considers TQM as a main factor that shape the strategies of towards a better higher educational institutions with a better satisfaction level (Oakland, 1993). The focus on TQM comes from its direct association with the organization itself, which is also a social technical system. Researchers argue that organizations are not merely technical systems because they also have human systems (Pike and Barnes, 1996). This idea implies that TQM improvement reflects the competitiveness, effectiveness, and structure of the whole organization (Dale, 1999). In additon, TQM is the correlational relation that brings together the individuals in the organization to produce high quality services, fulfilling the needs and expectations of the stakeholders.

Higher education organizations all over the world are experiencing a massive structural reformation, which is in accordance with the international reform plan launched in the late 1990s. In some countries, these plans involve comprehensive provisions for research, staff, and managers, including qualifications and related matters (Department of Education, 2000). A qualified management team, which competently monitors the quality of its strategies and considers future planning (Taylor, 2004) can lead the institute towards worldwide internationalization (Baidoun and Zairi, 2003). Researchers argue that improvement starts from the top of the organization, that is, those who are involved in TQM implementation (Jang, 2009). Likewise, the aspired development cannot be achieved without top level support and understanding (Juran, 1988). This understanding is one of the main features of TQM, as it provides a common language to all the members of the organization and facilitates the diffusion of commitment to quality (Mullen, 1996).

In developing countries, top management supports solving deficiencies for TQM (Kaplinsky, 1995). TQM implementation focuses on managerial leadership (Ready, 2006) and controlled by stakeholders (Johnes and Taylor, 1990). Moreover, Carroll (1994) argues that the lack of proper TQM strategies, techniques and obligation of top-level administrators is a pivotal obstacle facing quality improvement and proper TQM implementation (Carroll, 1994).

\subsection{Transformational Leadership}

Organizations have to provide an effective and transformed thinking about the nature of leadership. The new way of thinking can develop a new way of leadership that aims to achieve the objectives of the organization and removes the barriers confronting productivity (Arrington, 2010).

Moreover, the knowledge of transformational leadership is necessary to apply any leadership theory to practice. In this regards Northouse (2001) defined transformational leadership as a process that changes and transforms individuals. On the other hand, he added that transformational leadership is the skill to get people to wish for change, to improve, and to be led. Thus a transformational leader can bring success for a company by valuing its associates.

As an example, it can be referred to Sam Walton, founder of Wal-Mart. Visiting Wal-Mart stores in the whole country and meet his associates and appreciate their job in regards to company achievement is one of his concerns. In his biography, he gave "rules for success" one of which was to appreciate associates with praise (Walton and Huey, 1996).

There are four factors to transformational leadership which are as follows: idealized influence, inspirational 
motivation, intellectual stimulation, and individual consideration. Each factor will be discussed to help managers use this approach in the workplace.

- Idealized influence describes managers who are exemplary role models for associates. Managers with idealized influence can be trusted and respected by associates to make good decisions for the organization.

- Inspirational motivation describes managers who motivate associates to commit to the vision of the organization. Managers with inspirational motivation encourage team spirit to reach goals of increased revenue and market growth for the organization.

- Intellectual Stimulation describes managers who encourage innovation and creativity through challenging the normal beliefs or views of a group. Managers with intellectual stimulation promote critical thinking and problem solving to make the organization better.

- Individual consideration describes managers who act as coaches and advisors to the associates. Managers with individual consideration encourage associates to reach goals that help both the associates and the organization (Hall et al., 2008, p. 1).

Each factor plays a valuable role in transformation process. Once managers are strong role models, encouragers, innovators, and coaches, they are employing the "four I's" to assist "transform" their associates into better, more productive and successful individuals. Northouse (2001) by reviewing 39 researches related to transformational leadership found that those who revealed transformational leadership were more successful leaders and have better work outcomes. The result can be applied for both high- and low-level leaders in the public and private sectors (Northouse, 2001). Thus, it can be very advantageous for managers to apply the transformational approach in the workplace.

Transformational leaders express and promote a mission of major organizational change (Basham, 2010). In other words, TL is a leadership style that motivates employees to move beyond their own self-interest and perform beyond expectations for the greater good of the vision and goals of the organization (Ellis, 2007). The transformational leader generates an awareness of the mission or vision of the organization and develops employees to higher levels of capability and potential. Moreover, the transformational leader motivates employees to look beyond their own interests towards the interests that will benefit the group (Eyler, 2009; Domerchie, 2011). In other words, leaders who actively pursue new learning through action, thinking, feeling, and accessing others as resources report exhibiting TL behaviors more frequently (Agrusa, 2010).

TL provides the complexity of leadership roles and responsibilities in Libyan universities. Research continually demonstrates that all TL dimensions combined with organizational goals and processes designed to facilitate the professional development of faculty are at the heart of the learning organization. These elements of TL stimulate organizational members to think reflectively and critically about their own performance and to provide appropriate models of practices and values considered central to the organization (Hodgson).

Gary (2010) argues that TL occurs when individuals engage in the organization with others in such a way that they increase the motivation and morality of each other, resulting in a transforming effect in both the leader and the employees.

The present study defines TL as a style that recognizes that constant change encourages a collaboratively created vision for the organization (Button, 2003). TL involves guiding the organization through a revolutionary change by developing and gaining commitment to organizational visions, connecting to the employees, encouraging them to perform beyond expectations, and possessing important behaviors and characteristics that support organizational transformation (Gabriel, 2008).

\subsection{Transformational Theory of Leadership}

Many theories attempt to explain how employees learn and grow in the working environment. One of the main theories is the "thrive-strive model." Research argues that TL occurs when leaders inspire an atmosphere of trust, loyalty, and respect to the leader. These actions inspire employees to perform beyond what is required. The theory does not require any specific condition to exist but can occur in all organizations anywhere (Embry, 2010). As regards the mission, transformational leaders are responsible for producing performance beyond expectations, which are reflected in the new ways of their creative thinking. They also seek new techniques and opportunities, and prefer effectiveness to efficiency (Cooper, 2011). Domerchie (2011) identifies three primary categories encompassing the nine leadership functions that represent effective and transformational principal leadership behaviors. The first category is mission-centered, which begins by developing the vision for the organization. The second category is performance-centered, which highlights the importance of providing individuals with the necessary support. The third category is culture-centered, which emphasizes the importance of modeling 
organizational values and strengthening a productive organization culture. Walker (1993) describes TL as the convergence of shared decision-making, teacher empowerment, and school reform. Liontos (1993) defines the elements of TL as follows:

1. A collaborative, shared decision-making approach in which leaders believe that organizational goals can be better accomplished by shared commitment and collaboration

2. An emphasis on teacher professionalism and teacher empowerment in which leaders believe all teachers are capable of leadership and encourage them to be self-directed

3. An understanding of change, including how to encourage change in others; leaders are agents of change and are committed to educating students for the 21 st century (p. 2)

There are similarities in the models describing TL in education, such as collaborative work, encouraging and providing conditions for the self-direction of employees to learn and grow as professionals, and developing the leadership capacity of the organization. Such models suggest that leaders and members consider the development of organization as their own responsibility, and they prefer to be involved in envisioning and planning (Liontos, 1993). According to Conger (1999), individuals have certain characteristics that form their leadership behavior, giving them the capability to lead others towards the achievement of the set organizational goals. These elements include fulfilling employee self-actualization needs, empowering employees through intrinsic motivation, exhibiting confidence in the capability of the subordinates to attain higher levels of achievement, and enhancing collective identity (Iwuh, 2010).

Transformational leaders serve as role models for their employees. They hold the admiration and respect of employees who view their leaders as having extraordinary capabilities, persistence, and determination (Horn, 2009; Lippstreu, 2010). In addition, transformational leaders inspire those around them by providing meaning and challenge in the work of their employees. They encourage team spirit, enthusiasm, and optimism (Horn, 2009, p. 17). In their study, Bass and Avolio (1994) report that organizations flourish under effective transformational leaders and that employees report greater job satisfaction. They support the improvement of organizational systems and the maximization of employee talent to increase productivity results.

When transformational leaders are viewed as role models with a fixed goal and high level of expectations, employees set their own individual sights higher. When individual members of a team become more productive, the organization becomes more productive as a whole (Jameson, 2010). Leadership is an important factor affecting employee behavior. The theoretical basis highlighted in this section serves as a map that guides the research. Transformation leadership theory grew primarily from the work of Bernard Bass in the 1980s. Leithwood and his colleagues later created an adapted model of transformational leadership specific to the educational arena. This leadership model was well received in the education community as it was drastically different from the directive approach of instructional leadership that dominated the practice in the 1980s. The new model is characterized by individualized support for employees, personal vision and goal setting, and intellectual stimulation.

The emphasis of transformational leadership is the development of the organization. In contrast to instructional leadership, this approach to organizational improvement is from the bottom up, in which leadership may be shared with teachers. In his review of both instructional and transformational leadership, Hallinger (2003) characterized transformational leadership, saying that, "TL [transformational leadership] models may explicitly conceptualize leadership as an organizational entity rather than the property of a single individual, accounting for multiple sources of leadership" (Eyler, 2009).

The current research emphasizes the transformational leadership theory with its four dimensions, namely, shared values (e.g., sharing personal thoughts and beliefs with others), individualized consideration (e.g., supporting and developing the employees), idealized influence (e.g., challenging the status quo using new methods to solve the problem), and inspirational motivation (e.g., empowering employees and imagining a compelling vision). Thus, employees engage in work to achieve the performance goal when transformational leadership guides subordinates and advances their capability, commitment, and trust (Tsai and Chen, 2010).

Bass' (1985) model of transformational leadership has been selected as the prime model in the current research. In his model employees are encouraged by organizers to do tasks in a very adequate manner which exceeds expectations. He highlighted charisma as a significant component of transformational leadership (Bass, 1985). The findings of related studies confirmed this significant role that charisma play as it measure effective points such as satisfaction with the leader (Lowe, Kroeck, and Sivasubramaniam, 1996). Moreover, Bass (1999) stated that charisma and inspirational motivation are demonstrated when a leader envisions a enviable future, articulates how it can be reached, sets an example to be followed, sets high standards of performance, and shows determination and confidence. 


\section{Methods}

The current research paper clarifies the instruments employed to select relevant and up-to-date data, including implementing testing methods to maintain the instrument's validity and reliability. In addition, the section clarifies the methods used for data collection and data analysis.

\subsection{Population and Sampling}

The population of the current research consisted of seven universities in Libya which comprise a total number of (2302) faculty members from public higher education institutions (HEIs) distributed in 11 campuses. In addition, the sample of the current study consisted of (500) faculty members throughout simple random selection from the above mentioned population. Consequently, the samples have been selected to represent the population based on their components.

\subsection{Research Instrument}

The quantitative research was employed in the current research to originate the relationship between the variables of the study. Quantitative research tests objective theories by examining the relationship among variables. These variables are typically measured by instruments, and the numbered data can be analyzed using statistical procedures (Creswell, 2009). Moreover, the quantitative data assist in measuring the variables of the study, and provide a verification tool for the research hypotheses. Based on the quantitative data results, a cohort of new hypotheses is acquired from the data collection results on different variables.

Accordingly, a questionnaire have been adopted and slightly modified to cope with the current research explorations on the one hand, and the Libyan society, on the other hand. Questionnaires are a major data gathering instrument used in the field of education (Stone, 1978). Basically, "A questionnaire is an instrument for the collection of data, usually in written form, consisting of open and/or closed questions and other probes requiring a response from subjects" (Nunan, 1992: 231). The questionnaires used in the current study have been selected due to their objective nature, ease of application, high stability and honesty, and suit capability to the subject of the present study.

The questionnaire provides standardized measures consistent across all respondents, helping to ensure that the information about the respondents is comparable. Additionally, questionnaires enable the researcher to gather data on a study population (Creswell, 2002).

\section{Findings and Discussion}

The main reason of the current study was to explore the moderator influence of transformational leadership on the level of TQM implementation in the Libyan higher education sector. Therefore the findings in this section are depicted in two parts. Part one will project the argument of findings based on the descriptive findings particularly pertinent in relation with the level of responses found from the questionnaires and respondent profile. Further to this, it was followed by the filtering of data, factorial analysis of validity and realibility of the variable and analysis of the descriptive data. Meanwhile in the second part of the analysis, the reports are based on the qualitative and quantitative findings. The inferential statistical data initiated with the normality of data test, normal distribution test, linear, parallel variants for multiple regression analysis and hierarchical multiple regression analysis.

\subsection{Factor Analysis of Transformational Leadership Instruments}

The factor analysis of the confirmatory method with the extraction was limited to 4 factors implemented for the purposes of this study. In the confirmatory analysis factor, only the eigen value exceeding or equal to 1.00 on the loading of the factor exceeding 0.30 are considered as appropriate and as relevant criteria in selecting and acceptance as instrument items on this study.

As the initial step, all the 20 items proposed in measuring the 4 aspect of transformational leadership was classified. Then through the principle component analysis and varimax orthogonal and kaiser normalization, these items were extracted with limitation to 4 factors.

The findings of the confirmatory analysis in table 1 show that the 4 factors found to be prominent and vivid. 
Table 1. The structural factor and loading factor of varimax orthogonal for transformational leadership instruments

Collaboration of Factors

Factor 1 Factor 2 Factor 3 Factor 4

\begin{tabular}{|c|c|c|c|c|}
\hline Item & & & & \\
\hline S1 & & .61 & & \\
\hline $\mathrm{S} 2$ & & .54 & & \\
\hline S3 & & .53 & & \\
\hline S4 & & .66 & & \\
\hline S5 & & .79 & & \\
\hline S6 & & .58 & & \\
\hline S7 & .71 & & & \\
\hline S8 & .80 & & & \\
\hline S9 & .66 & & & \\
\hline $\mathrm{S} 10$ & .79 & & & \\
\hline S11 & .72 & & & \\
\hline S12 & .59 & & & \\
\hline S13 & & & .57 & \\
\hline S14 & & & .64 & \\
\hline S15 & & & .68 & \\
\hline S16 & & & .62 & \\
\hline S17 & & & & .53 \\
\hline $\mathrm{S} 18$ & & & & .78 \\
\hline S19 & & & & .71 \\
\hline S20 & & & & .79 \\
\hline Eigen Value & 10.53 & 1.94 & 1.38 & 1.0 \\
\hline Variance Percentsge & 52.65 & 8.69 & 5.43 & 4.2 \\
\hline Sphericity Bartlett Test & $1405.99 *$ & & & \\
\hline Df & 190 & & & \\
\hline Total Variance & 69.04 & & & \\
\hline
\end{tabular}

Note: Value of factorial analysis was rounded to two meaningful decimal points.

All the four factors that obtained to be imperatively lucid in this study are found to justify approximately 69.04 percents from the overall variance for the sample of this study. The indicators of matrix correlation, Kaiser-Meyer-Olkin Test (0.93) and Bartlett Sphericity Test $\left(\mathrm{X}^{2}=1405.99\right.$, df $\left.=190, \mathrm{p}<.05\right)$ obtained was significant. Thus, the effects of multicollinearity or singularity are found to be omitted or clearly do not occur. These result also confirms the compatibility of sampling to execute the factor analysis.

The dominant factors comprises of Factor 1 in congruent with the Idealized influence dimensions with value of variance at 52.65\%. Meanwhile Factor 2, well matched with the dimensions of Inspirational Motivation (variance of $6.69 \%$ ), Factor 3 harmonious with Intellectual Stimulation dimensions (variance of 5.44\%), and lastly Factor 4 attuned with the dimensions of Individualized Consideration (variance of 4.26\%).

Followed by this, the extended descriptive analysis was conducted to identify the intercorrelation between dimensions and the realibility of the transformational leadership dimensions. The findings from table 2 found to have in overall the Cronback Alpha realibility value in general for each dimensions between the range of 0.85 to 0.93 . These values indicates that the transformational leadership instruments are concrete and strong while possess high level of realiability. 
Table 2. Pearson Correlation and transformational leadership dimensions reliability

\begin{tabular}{llllll}
\hline Dimensions of Transformational Leadership & $\mathbf{1}$ & $\mathbf{2}$ & $\mathbf{3}$ & $\mathbf{4}$ & Cronbach Alpha $(\boldsymbol{\alpha})$ Value \\
\hline & & & & & \\
1.Idealized influence & - & - & - & - & .93 \\
2.Inspirational motivation & $.68^{* *}$ & - & - & - & .89 \\
3.Intellectual stimulation & $.58^{* *}$ & $.63^{* *}$ & - & - & .88 \\
4.Individualized Consideration & $.51^{* *}$ & $.57^{* *}$ & $.60^{* *}$ & - & .85
\end{tabular}

Note: $* *$ significant value at $\mathrm{p}<.01$

Additionally, the Pearson Correlation analysis was conducted to identify the relationship between the transformational leadership dimensions. The results of Pearson correlation shows a significant relationship between leadership dimensions at the level of $\mathrm{p}<.05$ with co-efficient correlation in the range of.51 to 68 .

\subsection{The Influence of Transformational Leadership on TQM}

To study the influences of transformational leadership variable on practices of TQM, the Multiple Regression analysis was utilized. For this purpose, the regression analysis was conducted on all the variables of the transformational leadership dimensions. The result of the regression analysis is shown in Table 3 below:

Table 3. Findings of standard ( $\beta$ ) beta regression value towards TQM dimension

\begin{tabular}{llllllll}
\hline & \multicolumn{2}{l}{ Total Quality Management } & & & & \\
& TQM1 & TQM2 & TQM3 & TQM4 & TQM5 & TQM6 & TQM7 \\
\hline Predictor & & & & & & & \\
Idealized influence & $.22 * *$ & .05 & $.13 *$ & .06 & .05 & .01 & -.09 \\
Inspirational motivation & .07 & $.14 *$ & .08 & .11 & $.19 * *$ & .04 & $.18^{*}$ \\
Intellectual stimulation & .04 & $-.13^{*}$ & .01 & $-.23 * *$ & -.05 & .04 & -.07 \\
Individualized Consideration & $.13 *$ & $.18^{* *}$ & $.27 * *$ & $.24 * *$ & $.17 * *$ & $.18^{* *}$ & $.20^{* *}$ \\
& & & & & & & \\
$\mathrm{R}^{2}$ & .15 & .06 & .17 & .06 & .10 & .05 & .06 \\
Adjusted $\mathrm{R}^{2}$ & .14 & .05 & .16 & .05 & .09 & .04 & .05 \\
F Value & $20.51 * *$ & $7.32 * *$ & $23.62 * *$ & 7.64 & $13.01 * *$ & $6.45 * *$ & $7.40^{* *}$ \\
\hline
\end{tabular}

Note: ${ }^{*} \mathrm{p}<.05,{ }^{* *} \mathrm{p}<.01 .(\mathrm{TQM} 1)=$ Leadership; $(\mathrm{TQM} 2)=$ Strategic Planning; $(\mathrm{TQM} 3)=$ Student and Stakeholder Focus; $(\mathrm{TQM} 4)=$ Information and Analysis; $(\mathrm{TQM})=$ Faculty and Staff Focus; $(\mathrm{TQM} 6)=$ Organizational Performance Results; (TQM7)= Educational and Support Process Management

The findings of the study as illustrated in Table 3 shows that the transformational leadership dimension has contributed between 6 to 17 percent of changes in variances in the practices of TQM through TQM1 to TQM 7.The findings from the table indicates that the transformational leadership dimension of Idealized influence $(\beta=.22$; $\mathrm{p}<.01)$ and Individualized Consideration $(\beta=.13 ; \mathrm{p}<.01)$ which has significant influences towards the practices of TQM Leadership.

Meanwhile, the transformational leadership dimensions of Inspirational motivation $(\beta=.14 ; p<.05)$ and Individualized Consideration $(\beta=.18 ; \mathrm{p}<.01)$ were found to have positive influences and significant towards the practices of TQM Strategic Planning. Nevertheless, the transformational leadership dimension of Intellectual stimulation $(\beta=-.13 ; p<.05)$ was found to have significant influences but negative at the practices of TQM strategic planning.

Then, the findings also shows that the dimensions of transformational leadership of Idealized influence $(\beta=.13$; $\mathrm{p}<.05)$ and Individualized Consideration $(\beta=.27 ; \mathrm{p}<.01)$ to have significant influences towards the practices of TQM student and Stakeholder focus.

Apart from that, the findings also shows that the transformational leadership dimension of Individualized Consideration $(\beta=.24 ; \mathrm{p}<.01)$ has positive influence and significant towards the practices of TQM information and analysis meanwhile the dimension of Intellectual stimulation of transformational leadership $(\beta=-.23 ; \mathrm{p}<.01)$ indicated to have negative influences. 
Meanwhile, the Inspirational motivation and Individualized Consideration of the transformational leadership found to have significant influences towards TQM practices in the practices of TQM Faculty and Staff Focus $(\beta=.19 ; \mathrm{p}<.01$ and $\beta=.17 ; \mathrm{p}<.01)$ and Educational and Support Process Management $(\beta=.18 ; \mathrm{p}<.01$ dan $\beta=.20$; $\mathrm{p}<.01)$. Moreover, inspirational leadership has the role of providing an effective criteria for motivating the entire organization and make clear an appealing view of the future, offer followers the opportunity to see meaning in their work, and challenge them with high standards (Kelly, 2003). Through transformational leaders encourage their followers to imagine and contribute to the development of attractive, alternative futures (Bass, Avolio, Jung \& Berson, 2003, p. 208). Meanwhile, the Inspirational motivation and Individualized Consideration of the transformational leadership found to have significant influences towards TQM practices in the practices of TQM Faculty and Staff Focus $(\beta=.19 ; \mathrm{p}<.01$ and $\beta=.17 ; \mathrm{p}<.01)$ and Educational and Support Process Management $(\beta=.18 ; \mathrm{p}<.01$ and $\beta=.20 ; \mathrm{p}<.01)$.

In addition, the results of the analysis indicate that, only the transformational leadership Individualized Consideration dimension was found to have influences and significant towards the practices of TQM Organizational Performance $(\beta=.18 ; \mathrm{p}<.01)$. In other words the findings indicated that the leader's actions is the most influential dimension among the TL dimensions that have a significant effect on TQM practices as the leaders are those who guide the followers toward reaching their respective levels of potential (Seaver, 2010; Jameson, 2010). Northouse (2001) states that, individuals who exhibited transformational leadership were more effective leaders with better work outcomes. This was true for both high- and low-level leaders in the public and private sectors (Northouse, 2001). Therefore, it can be very advantageous for managers to apply the transformational approach in the workplace.

Lastly, the findings of the study shows that only the transformational leadership Individualized Consideration dimension was found to have influences and significant towards the practices of TQM Organizational Performance Results $(\beta=.18 ; \mathrm{p}<.01)$.

\section{Implication}

The current research provides a starting point to promote quality improvement in Libyan universities. Furthermore, the study can supplement other data related to TQM implementation in Libyan universities. Through the analysis of the data the study draw conclusions about the factors that promote the use of TQM in higher education. The results also provided the target administrators with valuable and useful information on how to best implement and support TQM.

The study is considered to be the first in the Libyan context that takes into consideration the influence of transformational leadership on TQM implementation in HEIs.

\section{Recommendations}

A number of recommendations were proposed by the findings of the study which are significance to educators and policymakers, as well as to researchers. Transformational leadership has fundamental implications for employee performance.

Based on the findings, following are the recommendations and suggestions:

- The concerned parties in Libya should investigate the factors that lie behind proper TQM implementation in HEIs.

- More freedom should be given to the lecturers in sharing their ides The concerned parties in Libya should be aware of the relationship between TL and TQM implementation.

- The managers should establish friendly and respectable relationships with employees.

\section{Directions for Further Research}

Further research is desirable to investigate the impact of learning organization on TQM proper implementation. Other areas related to employee performance can be studied in order to improve the level of employee interaction in the institute. Furthermore, an in-depth research can explore the employee-manager relationship and its impact on the success of employee task accomplishment.

\section{References}

AbdulKarim, F. E. F. (2010). Development of Administrative Competences for Academic Departments Heads at Omar Al-Mukhtar University in Libya (Doctoral dissertation). Cairo University, Egypt.

Agrusa, E. D. (2010). Exploring the relationship of learning strategies and Transformational leadership for business managers (Doctoral dissertation). University of southern California, Los Angeles. 
Al-Awami, M., El-Hawat, A., \& Said, B. (2004). The march of higher education in Libya: The achievements and ambitions, 1st. Tripoli: The Libyan National Committee publications of the Education, Culture and Science Association and university faculty members in Libya.

Al-Badri, A. (2003). Internal Efficiency of the Department of Graduate Studies at Universities of Libya (p. 323). Benghazi: National Library.

Al-Bony, A. M. (2000). Psychological Measurement and Educational Evaluation. Tripoli, Dar al-Hikma.

Al-Fneash, A., Al-Sheabany, A., Bahmme, S., Falogy, M., Shglealah, A., \& Abused, F. (1998). Higher Education in Libya Comparative Study (pp. 138-141). Benghazi: National Library.

Al-Ghareeb, R. (1988). Evaluation and Psychological and Educational Measurement (p. 681). Cairo: Anglo Library.

Ali, B. A. (2005). Scientific Planning and Higher Education. Jrnaz, M. A. Higher Education in Libya. Tripoli: Faculty of arts, Tripoli University.

Ali, M., \& Shastri, R, K. (2010). Implementation of Total Quality Management in Higher Education. Asian Journal of Business Management, 2(1), 10-14.

Al-Mansouri, A, A. (2004). Educational Planning in Libya Origin. Development. Challenges (p. 178). Benghazi: National Library.

Al-Teab, M, A. (2009). Future Vision for the Development of Higher education in Libya. Education Systems in Arab Countries: The Abuses and Hopes (Doctoral dissertation). College of Education, Zagazig University, Egypt.

Arcaro, J. S. (1995). Quality in Education an Implementation Hand Book. Florida: St. Lucie Press.

Arrington, C. B. (2010). The Relationship between Transformational Leadership and Instructional Coaching (Doctoral dissertation). Alabama University, Alabama.

Bass, B. M. (1985). Leadership and performance beyond expectations. New York: The Free Press.

Bass, B. M., \& Avolio, B. J. (1989). Potential biases in leadership measures: How prototypes, lenience, and general satisfaction relate to ratings and rankings of transformational and transactional leadership constructs. $\begin{array}{llll}\text { Educational and Psychological } & \text { Measurement, }\end{array}$ http://dx.doi.org/10.1177/001316448904900302

Bass, B. M., \& Avolio, B. J. (1994). Improving organizational effectiveness through transformational leadership. Thousand Oaks, CA: Sage.

Brah, S. A., Tee, S. S. L., \& Madhu, R. B. (2002). Relationship between TQM and performance of Singapore companies. International Journal of Quality and Relicapability Management, 19(4), 356-379. http://dx.doi.org/10.1108/02656710210421553

Chaffee, E. E., \& Sherr, L. A. (1992). Quality: Transforming postsecondary education (p. 105). New York: Jossey-Bass.

Collins, D. B. (2001). Organizational performance: The future focus of leadership development programs. The Journal of Leadership Studies, 7(4), 43-54. http://dx.doi.org/10.1177/107179190100700404

Dale, B. G. (1999). TQM: An overview. In B. G. Dale (Ed.), Managing quality (3rd ed., pp. 3-33). Oxford, UK: Blackwell-Business.

Dettman, P. E. (2004). Administrators, Faculty, And Staff/Support Staff's Perceptions of MBNQA Educational Criteria Implementation at the University of Wisconsin Stout (Doctoral dissertation). Blacksburg, Virginia.

Etengoff, A. (2007). Building Transformational leadership through Integrated Leadership Development Programs. Nonprofit Management, 1.

Evans, J. R. (2008). Quality and Performance Excellence Management, Organization, and Strategy. Ohio: South-Western Thomson.

Garvin, D. A. (1991). How the Baldrige Award really works. Harvard Business Rev., 69(6), 80-93.

Ghanem, S. (1985). Changing planning policies in Libya. In M. M. Burru \& S. M. Ghanem (Eds.), Planning and development in modern Libya. London: Menus press.

Haddad, M. M., \& Bentaher, H. A. (2009). Measuring the Quality of the Performance of University Education in Libya: The Case of a Standard Form the University of the Seventh of October. Journal of Human Sciences, 
$7(42), 2$.

Hansman, E. M. (2007). Multifactor Leadership Questionnaire (Mlq) As Leadership Assessment Tool in Colleges and Universities: An Exploratory Study on Potential Interest in Higher Education (Doctoral dissertation). Capella University, Minnesota.

Hasheme, A. M. (2008). The Readiness of the University of Garyounis to Adopt the Philosophy of Quality Management Mole (Unpublished master's thesis). Academy of Graduate Studies Branch Benghazi.

Johnes, J., \& Taylor, J. (1990). Performance indicators in higher education. Maidenhead, United Kingdom: Open University press. http://dx.doi.org/10.1007/BF00133900

Johnson, J. R. (1998). Embracing Change: A Leadership Model for the Learning Organization. International Journal of Training and Development, 2(2), 141-150.

Juran, J. (1988). The quality function. In J. M. Juran (Ed.), Juran's quality control handbook (pp. 1-13). New York: McGraw-Hill. http://dx.doi.org/10.1111/1468-2419.00042

Kaplinsky, R. (1995). India's Industrial Development in the New Millenium: Sustaining Income Growth and Meeting Developmental Objectives. Brighton: Institute of Development Studies, mimeo.

Khademian, A. K. (2002). Working with culture: How the job gets done in public programs. Washington. DC: CQ Press.

King, S. W. (2002). Effective Leadership for Quality Achievement and Organizational Learning (Doctoral dissertation). Portland State University, Oregon.

Klefsjö, B., Wiklund, H., \& Edgeman, R. (2001). Six Sigma seen as a methodology for Total Quality Management. Measuring Business Excellence, 5(1), 31-35. http://dx.doi.org/10.1108/13683040110385809

Koch, J. V. (2003). TQM; Why Is Its Impact in Higher Education So Small? Total Quality Management Magazine, 15(5), 325-333.

Michael, R. K., Sower, V. E., \& Motwani, J. (1997). A comprehensive model for implementing total quality management in higher education. Benchmark. Qual. Manage. Technol., 4(2), 104-120. http://dx.doi.org/10.1108/14635779710174945

Millan, J. A. (1997). Appliccapability of the Premises of the Malcolm Baldrige National Quality Award Framework to Assessments of Community College Effectiveness (Doctoral dissertation). Illinois State University, Florida.

Mohammed, A. M. (1995). Social Research, a Study in Research Methods and Techniques (p. 362). Cairo: Dar Almarifa Aljamiya.

Moi, Y. S. (2006). Total Quality Management Models in Private Institutions of Higher Education in Malaysia: Two Case Studies (Doctoral dissertation). University of South Australia, South Australia.

Moyo, G. (2004). Re-Inventing Educational Leadership for School and Community Transformation: Learning from the Educational Leadership Management Development Programme of the University of Hare (Doctoral dissertation). Rhodes University, Grahamstown, South Africa.

Mullen, J. A. (1996). An Examination of Quality Improvement Initiatives in Higher Education (Doctoral dissertation). Arizona State University, Arizona.

Zairi, M., \& Baidoun, S. (2003). Understanding The Essentials of Total Quality Management A Best Practice Approach. Working Paper No (03/05) 20-21, 6 . 